\title{
Effect of Side-chain Substituents on Self-assembly of Perylene Diimide Molecules: Morphology Control
}

\author{
Kasuhik Balakrishnan ${ }^{1}$, Aniket Datar ${ }^{1}$, Tammene Naddo ${ }^{1}$, Jialing Huang ${ }^{2}$, Randy Oitker ${ }^{1}$, Max Yen $^{2}$, \\ Jincai Zhao ${ }^{3}$, and Ling Zang ${ }^{1}$ *
}

${ }^{1}$ Department of Chemistry and Biochemistry, Southern Illinois University, Carbondale, IL 62901.

Fax (618)453-6408 Email: lzang@chem.siu.edu; ${ }^{2}$ Materials Technology Center, Southern Illinois University, Carbondale, IL 62901; ${ }^{3}$ Key Laboratory of Photochemistry, Institute of Chemistry, Chinese Academy of Sciences, Beijing 100080, China.

\section{Supporting Information}

\section{Experimental Section}

\section{Materials}

N,N'-di(dodecyl)-perylene-3,4,9,10-tetracarboxylic diimide (DD-PTCDI) and N,N'-di(nonyldecyl)perylene-3,4,9,10-tetracarboxylic diimide (ND-PTCDI) were synthesized following the literature methods developed for the similar PTCDI molecules. ${ }^{1-3}$ The starting materials and all solvents (HPLC or spectroscopic grade) were purchased from Fisher and Aldrich and used as received.

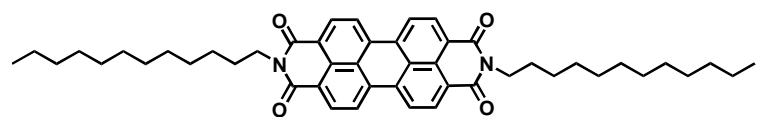

N,N'-di(dodecyl)-perylene-3,4,9,10-tetracarboxylic diimide (DD-PTCDI) was synthesized following the standard condensation method developed by Langhals. ${ }^{1}$ Briefly, $1.44 \mathrm{~g}(3.7 \mathrm{mmol})$ perylene3,4,9,10-tetracarboxylic dianhydride (Aldrich), $3.327 \mathrm{~g}(15.0 \mathrm{mmol})$ dodecylamine hydrochloride (Acros Organics), and $6 \mathrm{~g}$ imidazole (Acros Organics) were heated under argon at $140{ }^{\circ} \mathrm{C}$ for $3 \mathrm{~h}$. The reaction mixture was cooled to room temperature and dispersed in $100 \mathrm{~mL}$ ethanol followed by addition of $300 \mathrm{~mL} 2 \mathrm{M} \mathrm{HCl}$. The mixture was stirred overnight. The resulting dark-red solid was collected by vacuum filtration through a $0.45 \mu \mathrm{m}$ membrane filter (Osmonics). It was washed thoroughly with distilled water until the $\mathrm{pH}$ of washings turned to be neutral. The collected solid was dried in vacuum at $100{ }^{\circ} \mathrm{C} . \mathrm{R}_{\mathrm{f}}$ (silica gel/ $\mathrm{CHCl}_{3}$ : methanol 95:5) $=0.59 .{ }^{1} \mathrm{H}-\mathrm{NMR}\left(\mathrm{CDCl}_{3}\right): \delta=0.87(\mathrm{t}$, $\left.6 \mathrm{H}, 2 \mathrm{CH}_{3}\right), 1.54\left(\mathrm{~m}, 36 \mathrm{H}, 18 \mathrm{CH}_{2}\right), 1.77\left(\mathrm{~m}, 4 \mathrm{H}, 2 \beta-\mathrm{CH}_{2}\right), 4.21\left(\mathrm{~m}, 4 \mathrm{H}, 2 \alpha-\mathrm{CH}_{2}\right), 8.64(\mathrm{~m}, 8 \mathrm{H}$, perylene)

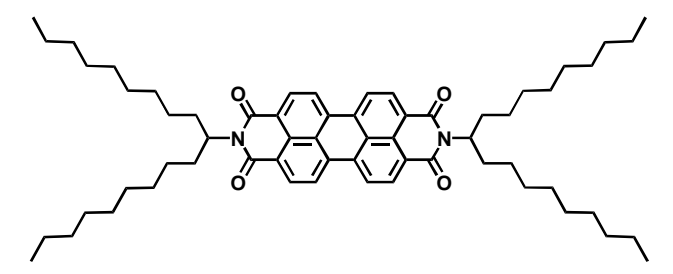

N,N'-di(1-nonyldecyl)perylene-3,4,9,10-tetracarboxylic diimide (ND-PTCDI) was synthesized following the standard condensation method developed by Langhals. ${ }^{1}$ Briefly, $1.44 \mathrm{~g}(3.7 \mathrm{mmol})$ perylene-3,4,9,10-tetracarboxylic dianhydride (Aldrich), $2.67 \mathrm{~g}(9.4 \mathrm{mmol})$ 1-nonyldecylamine (synthesized from di-n-nonyl ketone and ammonium formate according to literature, Chem. Abstr. $1965,63,13112 \mathrm{f}$ ), and $6 \mathrm{~g}$ imidazole were heated under argon at $120^{\circ} \mathrm{C}$ for $3 \mathrm{~h}$. The reaction mixture was cooled to room temperature and dispersed in $100 \mathrm{~mL}$ ethanol followed by addition of $300 \mathrm{~mL} 2 \mathrm{M}$ $\mathrm{HCl}$. The mixture was stirred overnight. The resulting red solid was collected by vacuum filtration 
through a $0.45 \mu \mathrm{m}$ membrane filter (Osmonics). It was washed thoroughly with distilled water until the $\mathrm{pH}$ of washings turned to be neutral. The collected solid was dried in vacuum at $100{ }^{\circ} \mathrm{C}$. $\mathrm{R}_{\mathrm{f}}($ silica gel/ $\left.\mathrm{CHCl}_{3}\right)=0.9 .{ }^{1} \mathrm{H}-\mathrm{NMR}\left(\mathrm{CDCl}_{3}\right): \delta=0.83\left(\mathrm{t}, 12 \mathrm{H}, 4 \mathrm{CH}_{3}\right), 1.25\left(\mathrm{~m}, 56 \mathrm{H}, 28 \mathrm{CH}_{2}\right), 1.86(\mathrm{~m}, 4 \mathrm{H}, 2 \alpha-$ $\left.\mathrm{CH}_{2}\right), 2.24\left(\mathrm{~m}, 4 \mathrm{H}, 2 \alpha-\mathrm{CH}_{2}\right), 5.18(\mathrm{~m}, 2 \mathrm{H}, 2 \mathrm{CH}), 8.67$ (m, 8H, perylene).

Pyrex glass cover slips (from Corning Inc.) were used as the support substrate for both the selfassembly (through solvent-vapor annealing, vide infra) and microscopy investigation of the nanostructures. Prior to use, a cover slip was cleaned with piranha reagent $\left(30: 70 \mathrm{H}_{2} \mathrm{O}_{2}(35 \%): \mathrm{H}_{2} \mathrm{SO}_{4}\right)$, followed by rinsing with water and methanol. ${ }^{2}$ Caution: Piranha solution is an extremely strong oxidizing reagent. The roughness of the glass surface thus cleaned was about $0.8 \mathrm{~nm}$ (Figure S10) as confirmed by the shear-force mode topography measurement performed with a scanning probe microscope (Aurora III, Veeco). Such a flat surface is suitable for both the surface fabrication and microscopy measurement of the nanobelts, which have thickness in the range of a few tens of nanometers.

\section{Solution based self-assembling}

The 1D self-assembly (nanobelts) of DD-PTCDI was performed using a so-called 'phase transfer' method. Briefly, the 1D growth of the molecular assembly was processed through slow crystallization at the interface between a 'good' and a 'poor' solvent, where the slow 'phase transfer' between the two solvents decreases the solubility at the interface. The poor solvent (e.g., methanol) is normally quite different (e.g., in term of polarity) from the good solvent (e.g., chloroform), thus providing the possibility to keep the two solvents in separate phases for an extended period. Typically, a larger amount $(10: 1 \mathrm{vol})$ of poor solvent was transferred atop a concentrated chloroform solution of DDPTCDI $(\sim 0.3 \mathrm{mM})$ in a test tube. Within minutes, red crystals formed at the interface, followed by slow diffusion into the upper phase of methanol. The nanobelts thus formed can be transferred and cast onto glass surface by pipetting. Hexane, another poor solvent for DD-PTCDI, was also used to fabricate the nanobelts following the same protocol.

\section{Surface based self-assembling}

Beyond the solution processing methods as described above, the self-assembly was also carried out using a solvent-vapor annealing technique recently developed in our lab. ${ }^{4}$ The annealing was performed in a desiccator having a lid with valve-controlled vent, which was connected to a vacuum pump. About $30 \mathrm{~mL}$ of solvent in a beaker was put in the chamber, followed by vacuum-pumping for about $5 \mathrm{~min}$. The chamber was then sealed by closing the vent, leading to saturation of the solvent vapor inside the chamber. The sample was kept in the vapor environment for an extended period (normally $12 \mathrm{~h}$ ) to complete the annealing process. The sample, typically a thin film on glass, was prepared by spin-casting a concentrated chloroform solution of PTCDI $(0.3-0.5 \mathrm{mM})$ at a speed of $1500 \mathrm{rpm}$.

\section{General spectral and structural characterization}

UV-vis absorption and fluorescence spectra were measured on a PerkinElmer Lambda 25 spectrophotometer and LS 55 fluorometer, respectively. Both the two instruments were equipped with a thermostat sample holder for temperature controlled measurement. The fluorescence spectra of the solid state were recorded with a modular fluorometer (Photon Technology International Inc.) which allows for highly sensitive measurement of the low emission of solid state DD-PTCDI. Differential Scanning Calorimetry (DSC) was performed using a Mettler-Toledo DSC 821. The sample was heated $\&$ cooled for two cycles between zero and a certain temperature above the melting point. X-ray diffraction was performed on a Rigaku D/Max-b, for which a Cu-Ka radiation $(\lambda=1.54 \AA)$ was used. The samples for X-ray measurement were prepared on glass cover slips by drop casting, followed by drying at room temperature.

\section{Microscopy characterization of molecular aggregates}

SEM measurement was performed with a Hitachi S570 (operated at $10 \mathrm{kV}$ ). The samples were prepared by casting the nanobelt suspension of DD-PTCDI (or nanoparticle suspension of ND-PTCDI) 
onto a clean glass slide, followed by drying in air. The dried sample was then annealed overnight in an oven at $45{ }^{\circ} \mathrm{C}$, followed by coating of gold. TEM measurement was performed with a Hitachi 7100 (operated at $75 \mathrm{kV}$ ). The samples were prepared by casting the nanobelt suspension of DD-PTCDI onto a silicon oxide or holey carbon film, followed by drying in air. The dried sample was then annealed overnight in an oven at $45{ }^{\circ} \mathrm{C}$. AFM measurement was carried out in tapping mode on a TopoMetrix Explorer using antimony doped silicon tip. The largest scanning area is $50 \times 50 \mu \mathrm{m}$, and the highest z-resolution is about $0.2 \mathrm{~nm}$. The samples were prepared by casting the nanocrystal suspension on a mica or glass surface, followed by drying in air for 1-2 h. Fluorescence microscopy imaging was carried out with a Leitz Orthoplan II microscope equipped with a real-color CCD camera for catching the emission image. Two filter sets were available for exciting the sample at different wavelength regions: FITC filter set with excitation at $450-490 \mathrm{~nm}$ and emission collected at $>515 \mathrm{~nm}$, and Rhodamine filter set with excitation at 530-560 nm and emission collected at $>580 \mathrm{~nm}$.

\section{More UV-vis and Fluorescence Spectra}
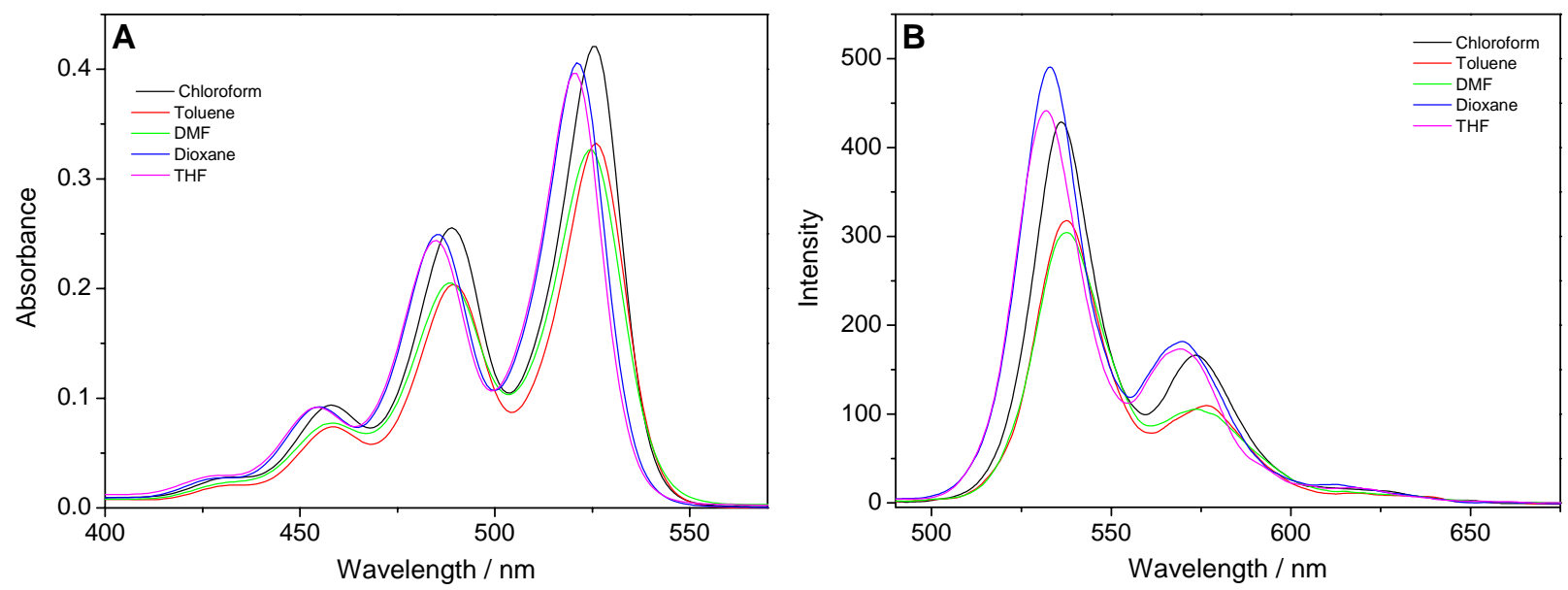

Figure S1. UV-vis absorption (A) and fluorescence (B) spectra of DD-PTCDI $(5.0 \mu M)$ homogeneously dissolved in some organic solvents. The spectral shift is not straightly dependent on the solvent polarity, because some specific solvent-molecule interaction also occurs for different solvents.
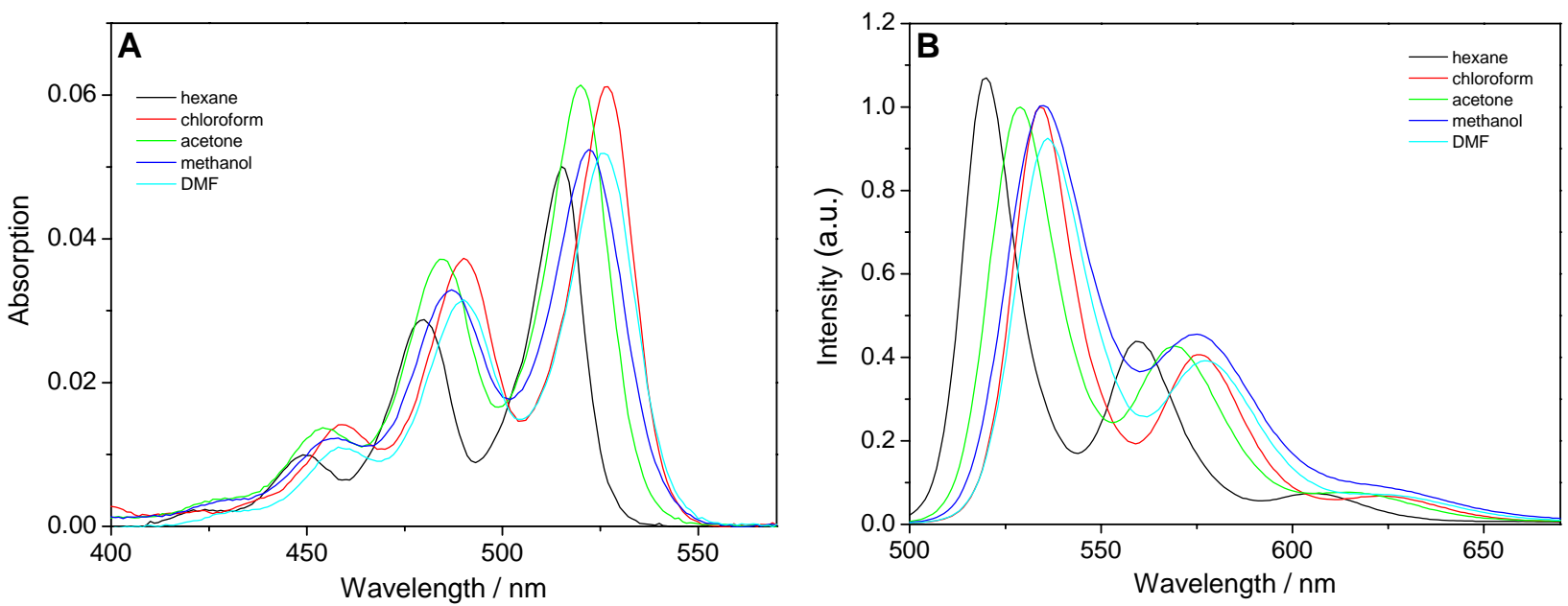

Figure S2. UV-vis absorption (A) and fluorescence (B) spectra of ND-PTCDI in some organic solvents $(0.7 \mu \mathrm{M})$. ND-PTCDI is soluble in most of the common solvents, and the spectra are similar as shown in this figure. The spectral shift is not straightly dependent on the solvent polarity, because some specific solvent-molecule interaction also occurs for different solvents. 

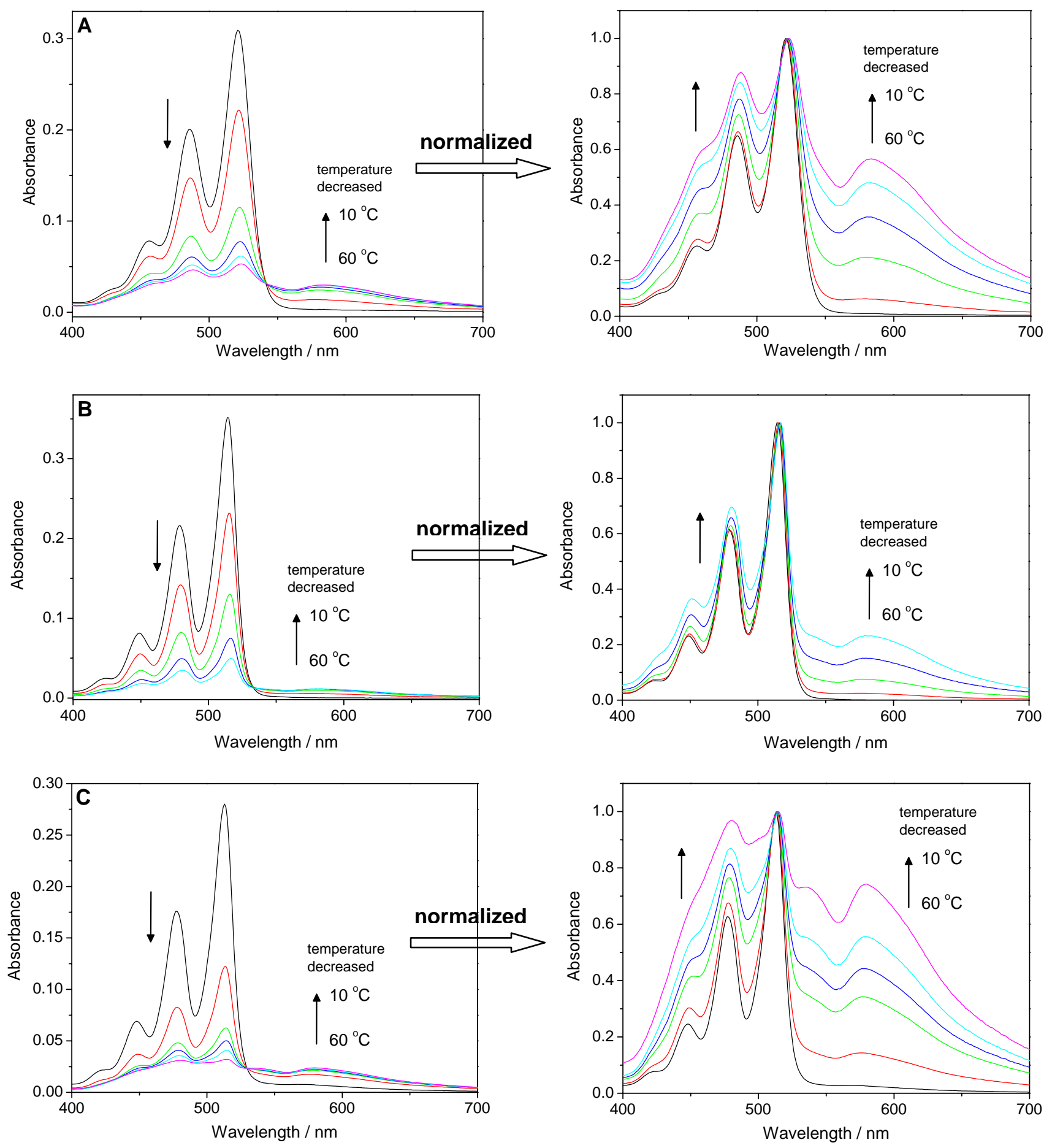

Figure S3. UV-vis absorption spectra of DD-PTCDI $(5.0 \mu \mathrm{M})$ in isopropanol (A), methyl cyclohexane (B) and heptane (C) at different temperatures. The spectra are normalized at the $0-0$ absorption maximum.

\section{More SEM Images}




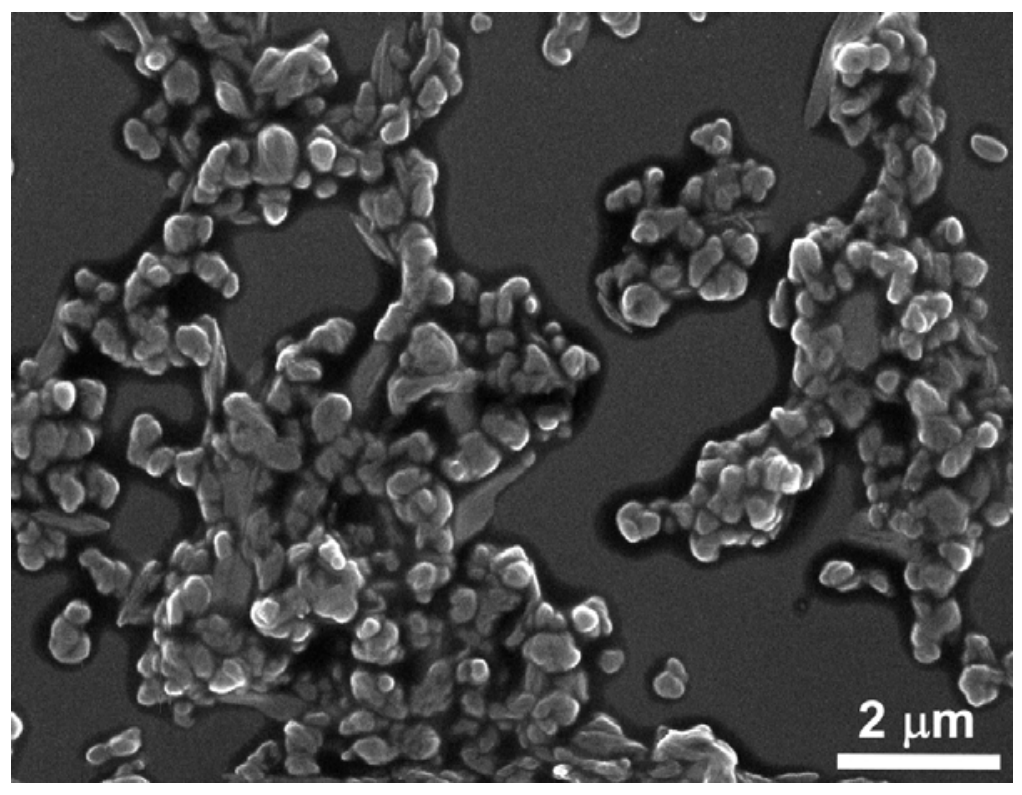

Figure S4. One more large-area SEM image of ND-PTCDI aggregates, the same sample as depicted in Figure 6.
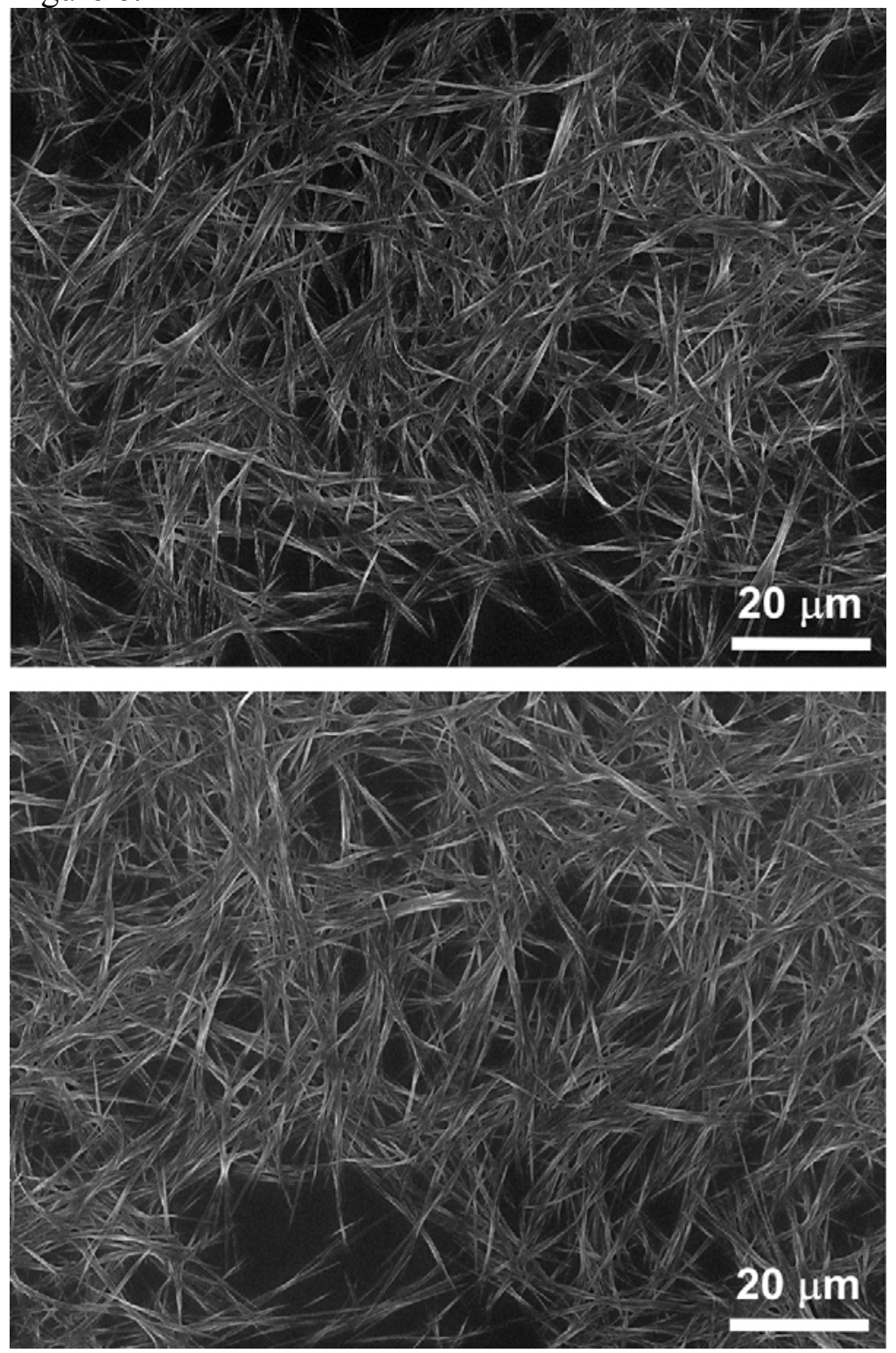
Figure S5. More large-area SEM images of DD-PTCDI nanobelts, the same sample as depicted in Figure 7.

\section{Fluorescence Microscopy Imaging}
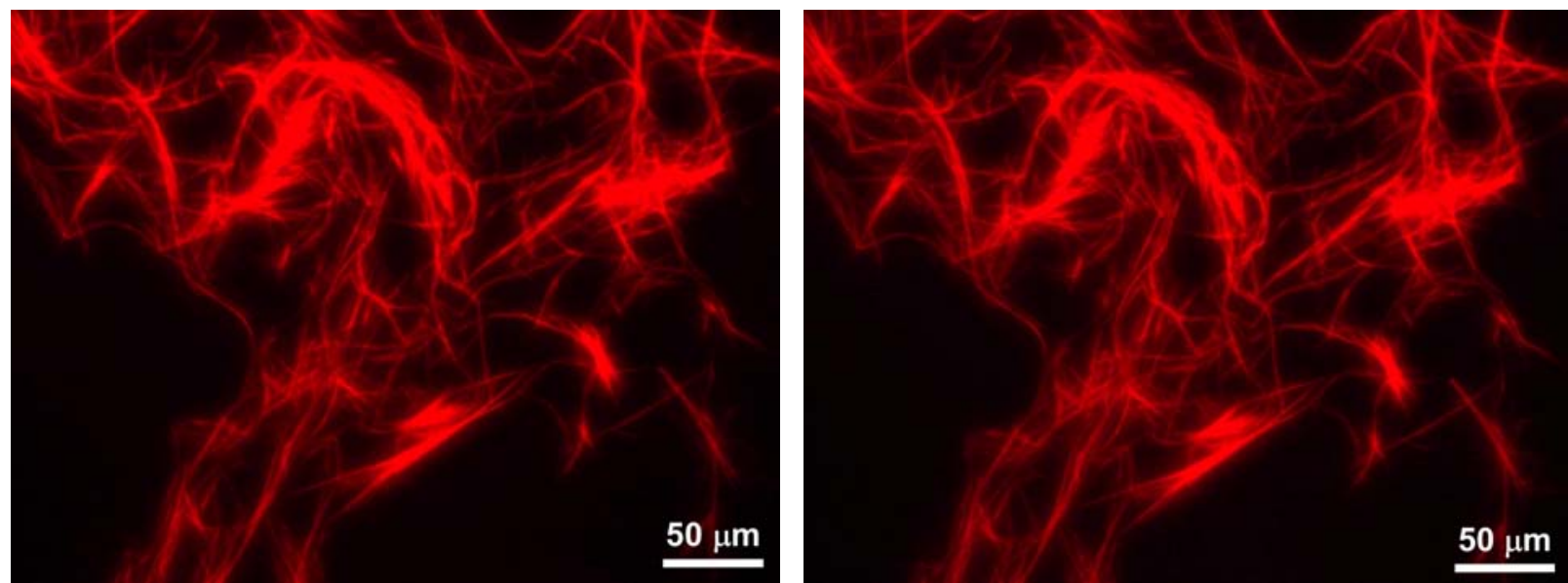

Figure S6. Fluorescence microscopy images of DD-PTCDI nanobelts deposited on glass with excitation at different wavelengths: (left) excitation: 450-490 nm; emission: $>515 \mathrm{~nm}$; (right) excitation: 530-560 nm; emission: > $580 \mathrm{~nm}$. The nanobelts were synthesized through phase-transfer between excessive methanol and a concentrated chloroform solution $(0.33 \mathrm{mM})$. Excitation at different wavelengths resulted in the same red color of emission, consistent with the fluorescence spectral measurement of the aggregate deposited on glass (Figure 4B), where the emission maximum was detected at $635 \mathrm{~nm}$.

\section{More TEM Images}

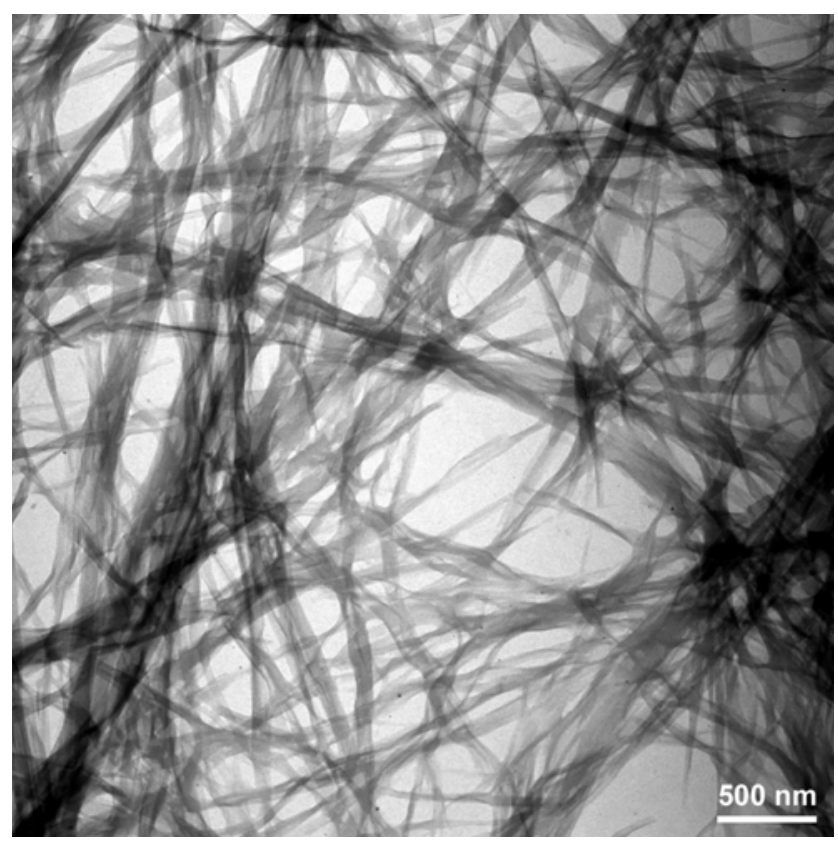

Figure S7. One more large-area TEM image of DD-PTCDI nanobelts deposited on silicon oxide film, the same sample as depicted in Figure 10A. 

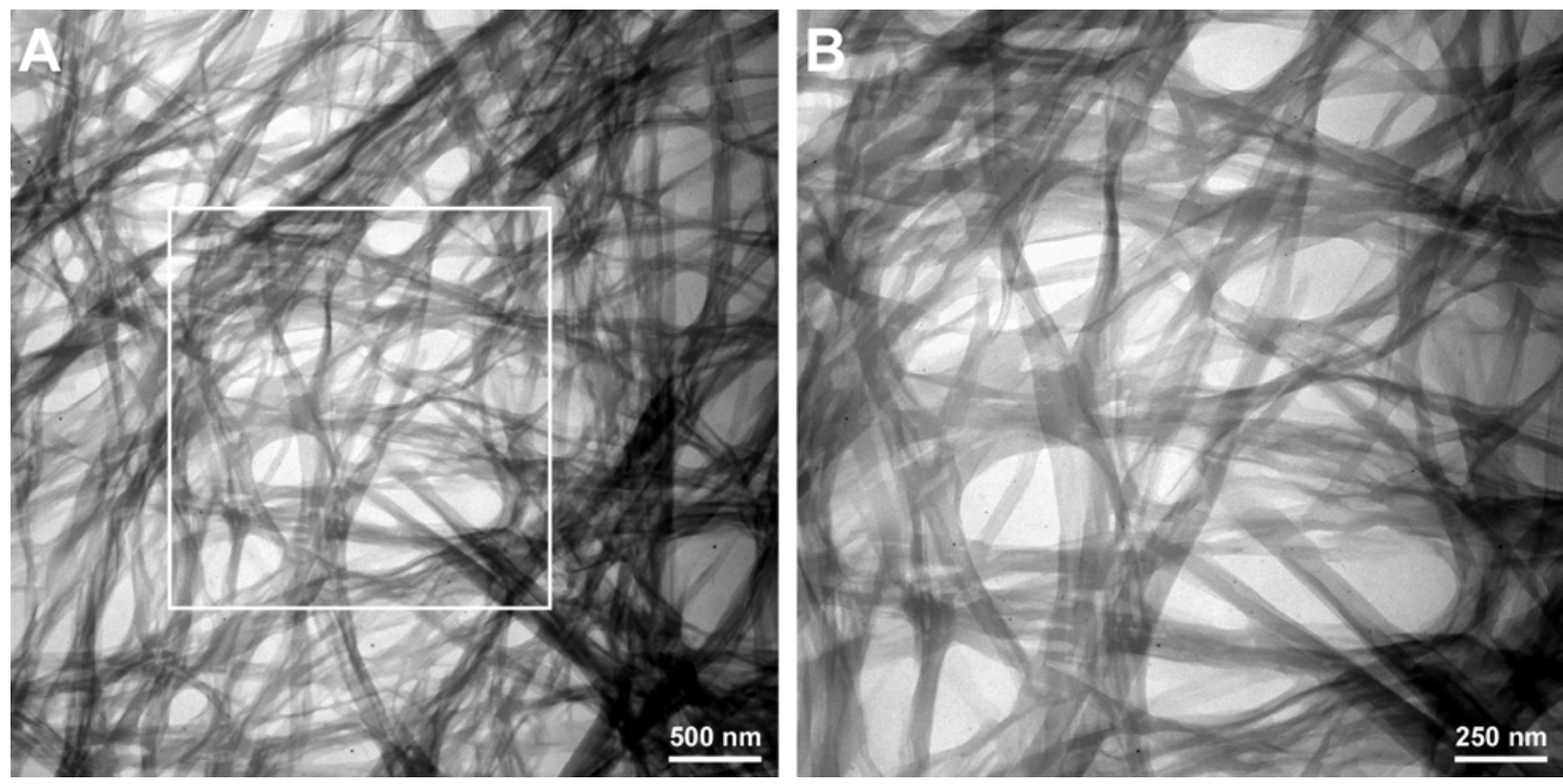

Figure S8. (A) One more large-area TEM image of DD-PTCDI nanobelts deposited on holey carbon film, the same sample as depicted in Figure 10C. (B) A zoom-in image of A.

\section{More AFM Images}

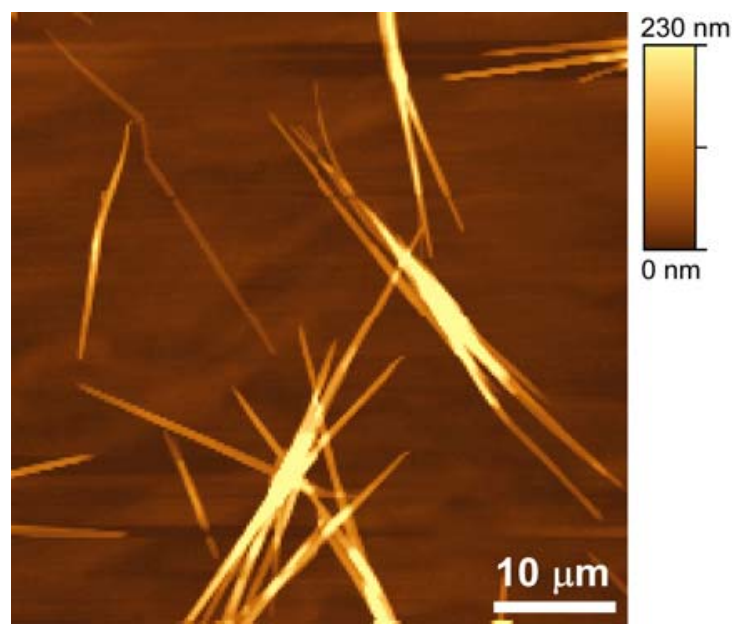

Figure S9. AFM image of DD-PTCDI nanobelts fabricated in situ on glass, the same sample as depicted in Figure 8. 

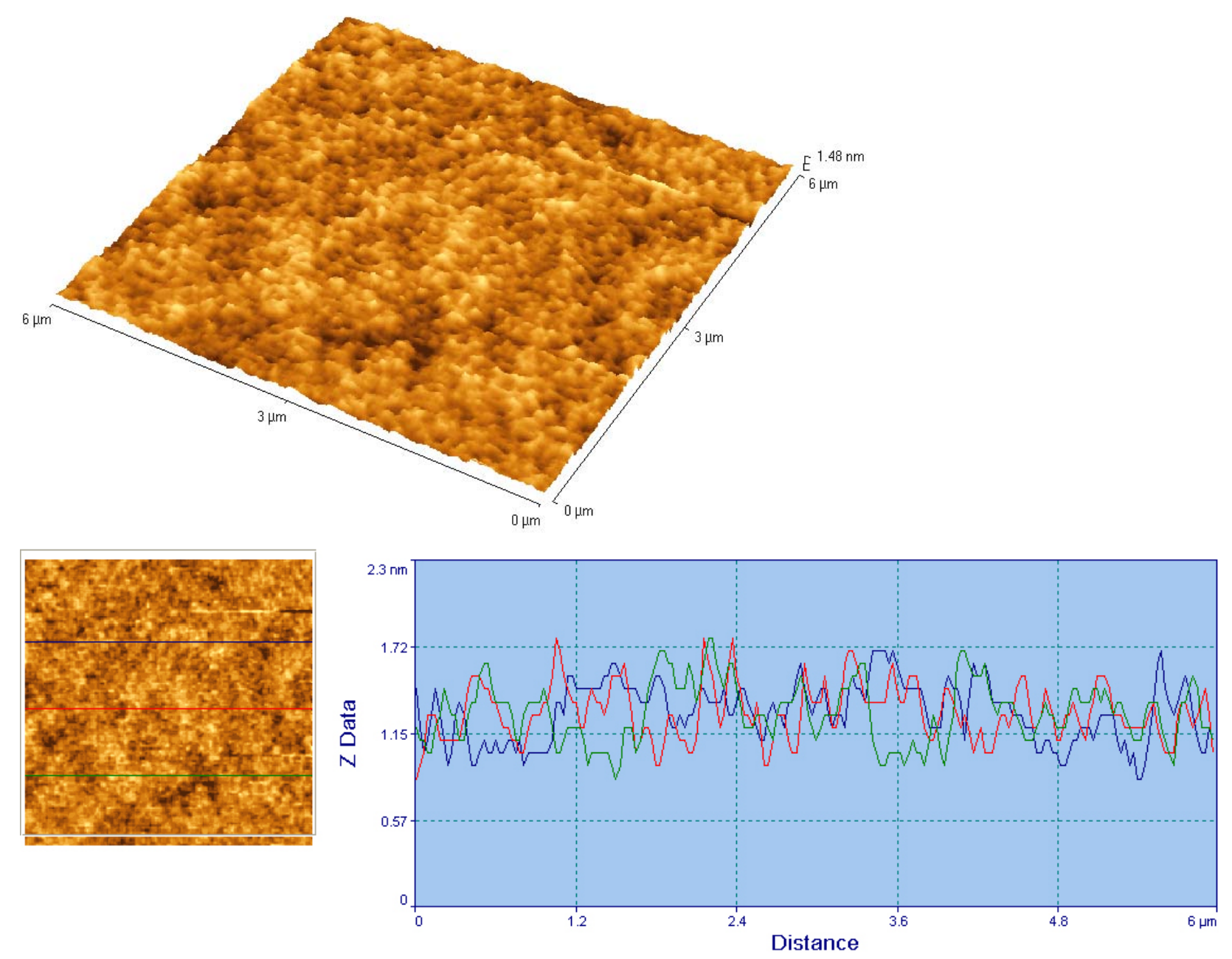

Figure S10. (top) 3D AFM image of a glass surface cleaned by piranha reagent; (bottom) the same image with three line-scan profiles showing the roughness $(\sim 0.8 \mathrm{~nm})$ of the surface.
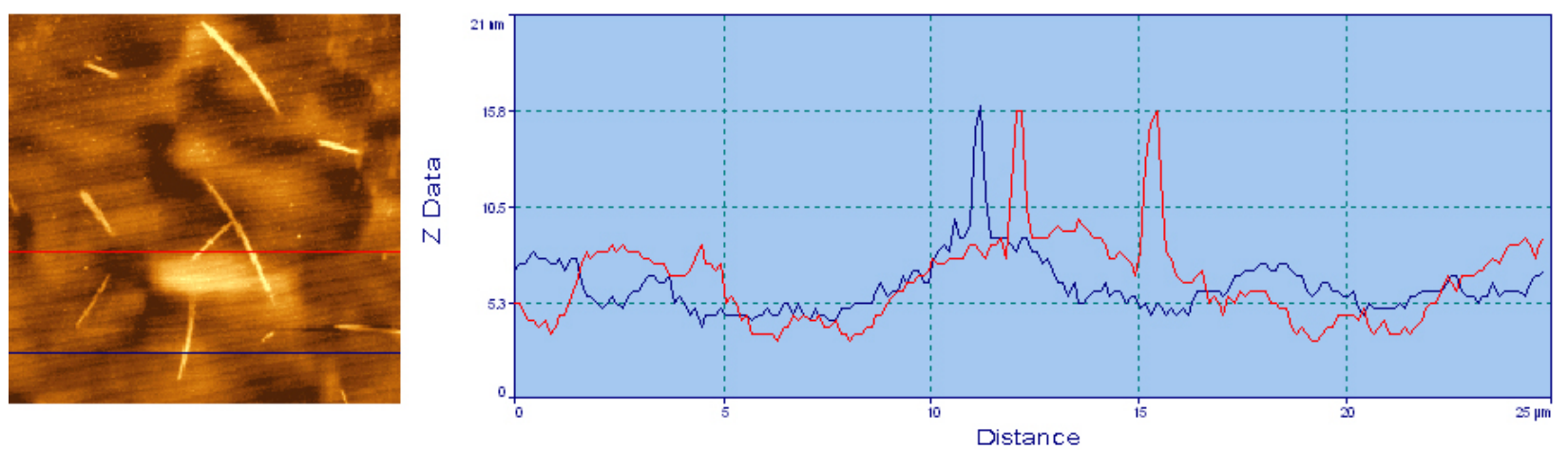

Figure S11. Two line-scan-profiles of the AFM image shown in Figure 11A for the DD-PTCDI nanobelts fabricated in situ on glass

\section{Optimization of Molecular Structure by Energy Minimization}

The energy-optimized conformation of the molecule was calculated by DFT (B3LYP/6-311g**//6$31 \mathrm{~g}^{*}$ ) using Gaussian 03. Shown below are the space-filling models of the calculated structure of DDPTCDI: 

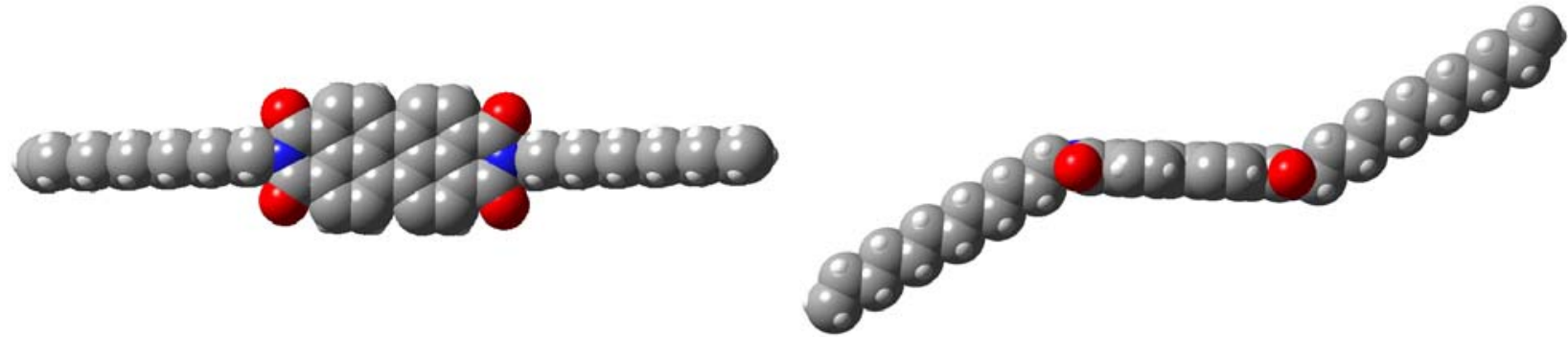

top view

side view

(1) Langhals, H. Heterocycles 1995, 40, 477-500.

(2) Zang, L.; Liu, R.; Holman, M. W.; Nguyen, K. T.; Adams, D. M. J. Am. Chem. Soc. 2002, 124, 1064010641.

(3) Balakrishnan, K.; Datar, A.; Oitker, R.; Chen, H.; Zuo, J.; Zang, L. J. Am. Chem. Soc. 2005, 127, 1049610497.

(4) Datar, A.; Oitker, R.; Zang, L. Chem. Commun. 2006, 1649-1651.

(5) Frisch, M. J. T., G. W.; Schlegel, H. B.; Scuseria, G. E.; Robb, M. A.; Cheeseman, J. R.; Montgomery, J. A.; Vreven, T.; Kudin, K. N.; Burant, J. C.; Millam, J. M.; Iyengar, S. S.; Tomasi, J.; Barone, V.; Mennucci, B.; Cossi, M.; Scalmani, G.; Rega, N.; Petersson, G. A.; Nakatsuji, H.; Hada, M.; Ehara, M.; Toyota, K.; Fukuda, R.; Hasegawa, J.; Ishida, M.; Nakajima, T.; Honda, Y.; Kitao, O.; Nakai, H.; Klene, M.; Li, X.; Knox, J. E.; Hratchian, H. P.; Cross, J. B.; Adamo, C.; Jaramillo, J.; Gomperts, R.; Stratmann, R. E.; Yazyev, O.; Austin, A. J.; Cammi, R.; Pomelli, C.; Ochterski, J. W.; Ayala, P. Y.; Morokuma, K.; Voth, G. A.; Salvador, P.; Dannenberg, J. J.; Zakrzewski, V. G.; Dapprich, S.; Daniels, A. D.; Strain, M. C.; Farkas, O.; Malick, D. K.; Rabuck, A. D.; Raghavachari, K.; Foresman, J. B.; Ortiz, J. V.; Cui, Q.; Baboul, A. G.; Clifford, S.; Cioslowski, J.; Stefanov, B. B.; Liu, G.; Liashenko, A.; Piskorz, P.; Komaromi, I.; Martin, R. L.; Fox, D. J.; Keith, T.; Al-Laham, M. A.; Peng, C. Y.; Nanayakkara, A.; Challacombe, M.; Gill, P. M. W.; Johnson, B.; Chen, W.; Wong, M. W.; Gonzalez, C.; Pople, J. A., Gaussian 03; Gaussian: Pittsburgh, PA, 2003. 